\title{
Erratum
}

Tiphane Andrade Figueira*, Nuno Tavares Martins, Lígia Ayres-Ostrock, Estela M. Plastino, Alex Enrich-Prast and Vinícius Peruzzi de Oliveira

\section{Erratum to: The effects of phosphate on physiological responses and carbohydrate production in Ulva fasciata (Chlorophyta) from upwelling and non-upwelling site}

https://doi.org/10.1515/bot-2021-2002

Erratum to: Tiphane Andrade Figueira, Nuno Tavares Martins, Lígia Ayres-Ostrock, Estela M. Plastino, Alex EnrichPrast and Vinícius Peruzzi de Oliveira. 2021. The effects of phosphate on physiological responses and carbohydrate production in Ulva fasciata (Chlorophyta) from upwelling and non-upwelling site. Botanica Marina, Volume 64, Issue 1, pages 1-11. (https://doi.org/10.1515/bot-2020-0051).

Mistakenly, the name and affiliation of Alex Enrich-Prast was assigned to the photo and bionote of Estela M. Plastino.
The correct bionote of Estela M. Plastino is as follows:

Estela M. Plastino, Marine Algae Laboratory, Institute of Biosciences, University of São Paulo, Rua do Matão 277, São Paulo 05508-090, Brazil

Estela M. Plastino, associate professor and researcher at the University of São Paulo, Institute of Biosciences. She is interested in cultivation, strain selection, reproduction, economic importance, physiology and genetics of marine macroalgae.

The publisher would like to apologize for the inconvenience caused.

*Corresponding author: Tiphane Andrade Figueira, Multiuser Unit of Environmental Analysis, Institute of Biology, Federal University of Rio de Janeiro, Rua Carlos Chagas Filho, 373 - Interbloco A/F, Rio de Janeiro, 21941-902, Brazil, E-mail: tiphane_af@yahoo.com.br. https://orcid.org/0000-0002-2481-2375 Nuno Tavares Martins, Lígia Ayres-Ostrock and Estela M. Plastino, Marine Algae Laboratory, Institute of Biosciences, University of São Paulo, Rua do Matão 277, São Paulo 05508-090, Brazil Alex Enrich-Prast, Department of Thematic Studies - Environmental Change, Linköping University, TEMA-huset, Entrance 37, Campus, Valla, Linköping, Sweden Vinícius Peruzzi de Oliveira, Multiuser Unit of Environmental Analysis, Institute of Biology, Federal University of Rio de Janeiro, Rua Carlos Chagas Filho, 373 - Interbloco A/F, Rio de Janeiro, 21941-902, Brazil 